\title{
Significant Properties of Steel Fiber \& Silica Fume Added Concretes According to Ordinary Concrete
}

\author{
Ziyafeddin Babayev (Corresponding author) \\ Faculty of Engineering and Architecture, Department of Civil Engineering, \\ Yozgat Bozok University, PO box 66000, Yozgat, Turkey \\ E-mail: ziyafeddin.babayev@bozok.edu.tr \\ Oguzhan Ates \\ Faculty of Engineering and Architecture, Department of Civil Engineering, \\ Yozgat Bozok University, PO box 66000, Yozgat, Turkey \\ E-mail: ates127@yahoo.com
}

\begin{abstract}
In this study, addition of steel fiber and silica fume to concrete on effect of behavior and mechanical properties of concrete was explained. By these additions, it is accented that a significant increase obtained on toughness, strength of tension and bending of concrete.
\end{abstract}

Keywords: Concrete, Steel Fiber, Silica Fume, Tension \& Bending Strength

DOI: $10.7176 / \mathrm{JSTR} / 7-02-02$

\section{Çelik Lif ve Silis Dumanı Katkılı Betonların Normal Betona Göre Üstün Özellikleri}

Özet

$\mathrm{Bu}$ çalışmada betona çelik tel ve silis dumanı ilavesinin betonun davranışına ve mekanik özelliklerine etkisi açıklanmıştır. Bu ilaveler ile betonun tokluğu, gerilme mukavemeti ve eğilmesinde önemli bir artış elde edildiği vurgulanmaktadır.

Anahtar Kelimeler: Beton, Çelik Lif, Silis Dumanı, Çekme ve Eğilme Dayanımı

\section{Giriş}

Modern yapılarda uzun yıllardır kullanılan ve gelecekte de kullanılacak olan beton, gerekli koşullarda tasarlanıp imal edildiğinde uzun yıllar boyunca hizmet verebilen en ekonomik ve dayanıklı yapı malzemesidir. Bileşenlerinin kolay temin edilebilir olması ve taze iken istenilen şeklin verilebilmesi nedeni ile yaygın olarak kullanıma sahiptir.

Beton heterojen ve boşluklu bir yapı malzemesidir. Betonun yapısındaki zayıflık kılcal boşluk ve betonun işlenebilirliği için gereğinden fazla konulan su miktarına bağlanmaktadır. Betondaki bu iki olumsuz etkeni aşağı çekmekle betonun niteliğinde önemli artışlar yapılabilmektedir. Kılcal boşlukları küçültmek, beton içerisindeki fazla suyu sonradan almak veya çimento tanelerini homojen bir şekilde dağıtan bir takım akışkanlaştırıcılarla su/çimento oranını düşürmek beton niteliğini arttırıcı yöntemlerdir.

Yapı sistemlerine ait normal betonların enerji yutma kapasiteleri düşük olduğundan, dış yükler artarak belirli bir limit değere ulaşınca yapıda göçme meydana gelir. Betona çelik lif donatılar veya çelik hasır donatılar eklenerek, daha sünek bir malzeme haline getirmek mümkün olmaktadır. Çelik tel donatılı betonlar, yüksek enerji yutma kapasitesine sahip olup, kırılma anında daha sünek davranış sergileyen malzemelerdir.

11 | P a g e

www.iiste.org 
Yüksek dayanımlı beton üretiminde silis dumanı da yaygın olarak kullanılmaktadır. Süper akışkanlaştırıcı katkılarla silis dumanının birlikte kullanımı betonda su/çimento oranını azaltırken kaliteli bir içyapı elde edilmesini de sağlamaktadır.

\section{2. Çelik Lif Katkılı Betonlar}

Beton özelliklerini değiştirerek iyileştirmek amacı ile taze beton içerisine, çeşitli yöntemler ile değişik miktarlarda lifler katılır. ACI 544'e göre lifin tanımı lif boyunun eşdeğer lif çapına bölünmesiyle elde edilen "boy/çap" (aspect ratio) oranı olarak kabul edilmektedir [1]. Bu orana kısaca "narinlik oranı" da denilmektedir. Eşdeğer lif çap1 ise; alanı lifin kesit alanına eşit bir dairenin çap1 olarak tanımlanmaktadır. Ancak bazı liflerin uzunluklarının ve çaplarının farklı değerler alması ve cam liflerde olduğu gibi liflerin demet şeklinde olması nedeniyle liflerde, sadece boy/çap oranına göre sınıflandırma yapmak mümkün olmamaktadır.

Beton bileşimine katılan çelik lifler, çoğunlukla sert çekilmiş düşük karbonlu (C1008) çelikten üretilmektedir. Yüksek ve üniform çekme gerilmesine karşılık düşük uzama özelliği gösterir. Çekme gerilmeleri ortalama olarak $1200 \mathrm{MPa}$ olup elastik limitleri \%0.2'nin altındadır.

Genel olarak uygulama alanlarına göre üretilen çelik lif tipleri Şekil 1'de görülmektedir [2].

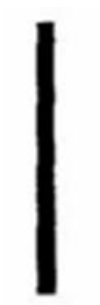

Düz

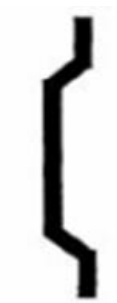

Çengelli

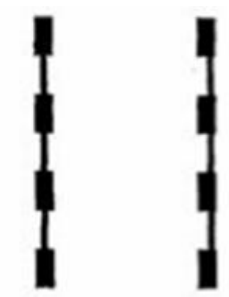

Çiftkenar

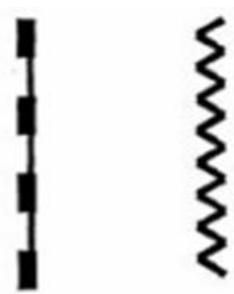

Kivrıml1

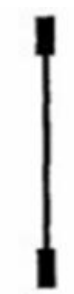

Paletli

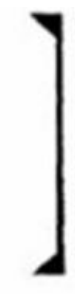

Sonlanmıș

Şekil 1. Çelik lif tipleri ve şekilleri

Betonun çekme dayanımını artırmak amacıyla yapılan ilk çalışmalar 1963 yılında Romualdi ve Mandel tarafindan başlatılmıştır [3]. Bunlar betonun çekme bölgesinde birbirine paralel olarak yerleştirilmiş ince teller bulunan kirişler üzerinde deneyler yaparak kirişin eğilme dayanımının arttı̆̆ını ve kırılma yüküne çok yaklaşılıncaya kadar çatlakların fazla büyümediğini gözlemişlerdir. Eğilme deneylerinde maksimum eğilme yükündeki şekil değiştirmelerin artan lif miktarı ve boyutunun bir fonksiyonu olarak önemli bir artış gösterdiği belirtilmektedir. Betonun içine liflerin katılmasının ilk çatlak oluşumunda, gerilme ve deformasyonlar üzerinde önemli etkisi vardır. Fakat bu etki maksimum yüklemede elde edilen sonuçlara göre daha azdır.

Shah ve Rangan, yaptıkları çalışmada betonun basınç ve eğilme dayanımına lif miktarı, lif boyu ve liflerin karışım içerisindeki dağılımı gibi faktörlerin etkilerini araştırmışlardır [4]. \%0.25-\%1.25 arasında değişen lif miktarları ile üretilen betonların eğilme dayanımlarının lif miktarının artışıyla doğru orantılı olarak arttığını görmüşlerdir.

Harris, Varlow ve Ellis, 1972 yılında lifli betonun kırılma davranışını incelemişlerdir [5]. Deneysel sonuçlardan yararlanılarak kırılma mekaniği esaslarını lifli betonlara uygulamayı tasarlamışlardır. Kiriş numuneleri üzerinde yapılan eğilme deneylerinde elde edilen sonuçlara göre kırılma işi; lif miktarına, karışım içerisindeki liflerin dağılımına ve lif tipine bağlı olarak belirlenmiştir. Hacimsel olarak \%2 lif miktarında toplam kırılma işinin artmakta olduğu görülmüştür.

Traine ve Mansur, 1972 yılında tek ve iki eksenli gerilme hallerinde normal ve lifli betonların basınç dayanımları ile gerilme şekil değiştirme davranışlarını araştırmışlardır [3]. Karışımlarda narinlik oranı 33 ve 60 olan iki tip lif, hacimce $\% 0.5, \% 1$, ve \%1.5 oranlarında kullanılmıştır. Elde ettikleri sonuçlara göre; lifli betonların tek eksenli basınç dayanımlarında, lif miktarı ve tipine bağlı olarak, normal betonla kıyaslandığında artma veya önemli bir değişiklik görülmemiştir. Tek eksenli gerilme halinde narinlik oranı 60 ve lif miktarı \% 1.5 olan karışımlar da basınç \%22 oranında artmıştır.

Bayramov ve arkadaşları çelik tel içeriği ve narinliğinin artmasıyla betonların göçmeye kadar enerji yutma kapasitelerinin arttığını ve betonların normal betonlara kıyasla daha sünek bir davranış

12 | P a g e

www.iiste.org 
gösterdiğini ifade etmişlerdir [6].

Beton harcı içerisine lif katılması, betonun eğilme mukavemeti, çekme mukavemeti, elastisite modülü, darbe direnci, yorulma dayanımı, parçalanma ve kırılma dayanımında ve tokluğunda artışlar meydana getirmektedir [1].

Çelik lif katkılı betonların kullanım alanları çok geniştir. Dünyada lifli betondan baraj, kanal, tünel, yol inşaatında istifade edilmektedir. Lifli betonun üstün nitelikleri kesit kalınlıklarının azaltılmasını mümkün hale getirdiğinden, ince kabuk yapılarda, kubbelerde, katlanmış plaklarda ve çeșitli mimari nedenlerle ince olması gereken yapı elemanlarında kullanılmaktadır.

\section{Silis Dumanlı Betonlar}

Silis dumanı; silisyum metali veya ferro silisyum alaşımlarının üretimi sırasında kullanılan elektrik ark firınlarında yüksek saflıktaki kuvarsitin kömür ve odun parçacıkları ile indirgenmesi sonucu elde edilen çok ince taneli tozdur. Fırınların düşük sıcaklıktaki üst bölümlerinde $\mathrm{SiO}$ gazı hava ile temas ederek hızla okside olur ve amorf $\mathrm{SiO}_{2}$ olarak yoğunlaşarak silis dumanı bileşiminin hemen hemen tamamını oluşturur. $\mathrm{Bu}$ malzeme mikrosilis, silis tozu veya silika füme gibi isimlerle de anılmaktadır. Silis dumanı amorf yapıya sahip olduğundan ve yüksek miktarda $\mathrm{SiO}_{2}$ içerdiğinden mükemmel bir puzolanik malzemedir [7].

Silis dumanı kullanılarak üretilen betonların fazla miktarda karışım suyuna ihtiyacı vardır. Bunu karşılayabilmek için su azaltıcı katkılarla birlikte kullanılmaları gerekmektedir. Çok ince taneli olduğundan ve terlemeyi azalttığından beton yüzeyinin düzeltilmesi işlemi güçleşmektedir. Çoğu zaman plastik büzülme çatlaklarına neden olan silis dumanı genellikle betonun koyu renk kazanmasına sebep olur [8].

Silika füme ferrokrom tesislerinin bacalarında tutulan ultra incelikteki silis tozlarıdır. Yaygın olarak çimento ve beton sektöründe kullanılmaktadır. Özellikle beton üretiminde silis dumanı gibi ultra incelikteki tanelerin kullanımı, yoğunluğun arttırılması dolayısıyla boşlukların azaltılması taze betonun stabilitesinin geliştirilmesi için önemlidir.

Normal Portland çimentosundan yaklaşık 100 kat daha ince olan silis dumanı, bu sayede çimento tanelerinin arasında kalan boşlukları doldurur ve ince boşluklardaki suyun serbest suya dönüşmesini sağlar. Buna karşılık Normal Portland çimentosuyla kıyaslandığında çökme değerlerinde yaklaşık \%70 oranında bir azalma durumu meydana gelir. Bu olumsuzluğu bertaraf etmek için günümüzde süper ya da hiper akışkanlaştırıcılar kullanılmaktadır [7].

Silis dumanının süper akışkanlaştıııcılarla birlikte kullanımı ile beton dayanımlarında yüksek değerlere ulaşılabileceği kanıtlanmıştır. Bu durum azalan boşluk oranı ve silis dumanının geçiş zonundaki aktivitesi ile açıklanabilir. Silis dumanı betonda kullanıldığında, çimentonun hidratasyonu esnasında ortaya çıkan serbest kireci bağlayarak kalsiyum silikat hidrateyi $(\mathrm{CSH})$ oluşturur. Serbest kirecin bağlanması neticesinde çimento hamuru daha yoğun mikro boşluk yapısına sahip olur, ayrıca ince silis dumanı taneleri agrega-çimento hamuru ara yüzeyini sıkılayıp güçlendirerek daha yüksek dayanımlara ulaşabilen betonlar elde edilmesini sağlar $[7,9,10]$.

Silis dumanı katkılı betonda kür koşulları da geçirimlilik için önemli bir etkendir. Aynı bileşene sahip, aynı oranda silis dumanı içeren iki ayrı betondan kür uygulanmış olanında çok daha düşük seviyelerde kılcal su emme ve klor geçirimliliği görülmektedir. Bu durum özellikle silis dumanı oranı arttıkça kendini daha da göstermektedir. Bu nedenle silis dumanı oranı arttırıldıkça, kür koşullarına daha çok özen gösterilmektedir.

Şimşek ve arkadaşları, çelik lifli betonlarda $\% 0, \% 2.5, \% 5$ ve $\% 10$ oranlarında silis dumanı, çimento ile yer değiştirerek kullanılmıştır [11]. Numuneler, C25 sınıfında, su/çimento oranı, 0.50 olacak şekilde seçilmiş ve masa tipi vibratörle sıkıştırılarak üretilmişlerdir. 100x100x500 mm boyutlarında üretilen prizma numuneler üzerinde, orta noktasından yüklemeli eğilme deneyi yapılmıştır. Sonuç olarak, çelik lifli betonlara $\% 10$ silis dumanı katılması, lifli betona göre eğilme dayanımında, 28 günde $\% 23.5,90$ günde $\% 30.8$ ve 120 günde de $\% 18.3^{\prime}$ 'lük bir artış sağlamıştır. Silis dumanlı lifsiz betonların, eğilme dayanımlarında en yüksek değere $\% 2.5$ silis dumanı oranında ulaşılmış, $\% 5$ ve $\% 10$ oranlarında ise azalma görülmüştür.

Köksal ve arkadaşları, silis dumanı ve çelik telin betona katılmasıyla elde edilen numunelerin bazı mekanik özellikleri üzerindeki değişiklikleri araştırmışlardır [12]. Antalya ferrokrom tesislerinden elde edilen silis dumanı ve narinlikleri 65 ve 80 olan iki tip çelik tel çalışmada kullanılmıştır. Net su/çimento oranı 0.38 ve referans çökmesi $12(10-14) \mathrm{cm}$ olan betonlar üretilmiştir. Silis dumanının betona katılma oranları $\% 0, \% 5, \% 10$ ve $\% 15$, çelik tellerin katılma oranları ise $\% 0.5$ ve $\% 1$ 'dir. Taze betonlar üzerinde işlenebilirlik, hava içeriği ve birim ağırlık deneyleri yapılmıştır. Sertleşmiş beton

13 | P a g e

www.iiste.org 
numuneleri üzerinde ise basınç dayanımı, yarmada çekme dayanımı ve eğilme dayanımı deneyleri yapılmıştır. Ayrıca, kapalı çevrim sehim kontrollü yükleme çerçevesinde ASTM C 1018 standartlarına [13] uygun olarak yapılan eğilme deneyi ile numunelerin yük-sehim eğrileri elde edilmiş ve toklukları belirlenmiştir. Silis dumanı ve çelik telin birlikte kullanılması betonların yarma ve eğilme dayanımlarını belirgin bir ölçüde artırmıştır.

Erdoğdu ve arkadaşları, yaptıkları çalışmada silis dumanı ikamesinin katkılı çimento ile üretilen betonun basınç dayanımına etkisi Portland çimentosu ile üretilen betonun basınç dayanımı ile karşılaştırmalı olarak incelenmiştir [14]. Bu amaçla Portland çimentosu ve katkılı çimento olmak üzere iki tip çimento kullanılmıştır. Çalışmada 0.60 su/bağlayıcı oranında toplam bağlayıcı 300, 350 ve 400 $\mathrm{kg} / \mathrm{m}^{3}$ olacak şekilde çimento miktarının $\% 9$ ve \%18 oranında silis dumanı ilave edilerek beton üretilmiştir. Karşılaştırma amacı ile her bir çimentodan silis dumanı içermeyen üretimler de gerçekleştirilmiştir. Basınç dayanımları 7 ve 28 gün sonunda elde edilmiştir. Çalışmadan elde edilen bulgulara göre silis dumanı katkılı çimento ile üretilen betonlarda gerek 7 gün gerekse 28 gün sonunda basınç dayanımı üzerinde göz ardı edilmez olumlu katkısı gözlenmiştir. Bu katkı \%9 oranında silis dumanı ikamesi ile 7 gün sonunda $\% 50$ mertebesine ulaşırken, $\% 18$ oranında silis dumanı ikamesi ile 28 gün sonunda $\% 60$ mertebesinde olmaktadır.

Ekinci ve Yeğinobalı, çalışmalarında silis dumanı katkılı betonların çarpma dayanımı belirli bir ağırlığın belirli bir yükseklikten düşürülmesi sonucu, beton numune özelliklerinde meydan gelen değişikliklerin izlenmesi yöntemi araştırılmışır [15]. Sonuçlara göre, silis dumanı katkıları betonun çarpma dayanımını olumlu olarak etkilemektedir. Ancak, katkı oranının \%20'nin üstüne çıkarılması durumunda olumlu etki, statik yük dayanımı üzerindeki etkiden farklı olarak, biraz azalabilmektedir.

\section{Sonuçlar}

Araştırma sonuçları incelendiğinde çelik tel ve silis dumanı katkılı betonlarda katkısız betonlara nazaran çarpma dayanımının, tokluğun, çekme ve eğilme mukavemetinin arttığı tespit edilmiştir. Tokluğun yüksek olmasından dolayı bu tip betonların deprem bölgelerinde kullanılması çok daha önemlidir.

\section{Kaynakça}

[1]. ACI COMMITEE 5441982 Amerikan concrete Institute standartı

[2]. Sancak,E.,1998,"Hafif Agregalı Beton Blokların Mekanik Özellekleri Üzerine Çelik Lif Kullanımının Etkisi”,S.D.Ü.,Fen Bil. Ens., Yüksek Lisans Tezi,Isparta

[3]. Ünal,O.,1994,’Isıl İşlem Uygulamasının Lifli Beton Özelliklerine Etkisi”,,ITÜ, Fen Bilimleri Enstitüsü, Doktora Tezi, İstanbul.

[4]. Shah,S.P., Rangan, B.V., 1971,'Fiber Reinforced Concrete Propertes", ACI Journal,pp.126135, Feb.

[5]. Yiğiter, H., 2002, "Yüksek Performanslı Betonların Süneklik Özelliklerinin Araştırılması", DEÜ, Fen Bilimleri Enstitüsü, Yüksek Lisans Tezi, İzmir.

[6]. Bayramov, S., Taşdemir, C., Taşdemir, M.A., Optimum design of cement-based composites materials using statistical response surface method,Fifth International Congress on Advanced in Civil Engineering, İTU,İstanbul, Turkey, September 25-27, pp.725-734.

[7]. Yeğinobalı, A., 2007, Silis Dumanı ve Çimento ile Betonda Kullanımı, Türkiye Çimento Müstahsilleri Birliği Ar-Ge Enstitüsü, Ankara.

[8]. Topçu, İ.B., 2006, Yapı Malzemeleri ve Beton, Şahvar Offset, Eskişehir.

[9]. Mazloom, M., ve Ramezanianpour, A.A. ve Brooks, J.J., 2004. Effect of Silica Fume on Mechanical Properties of High-Strength Concrete, Cement and Concrete Composites, 26,pp.347-357.

14 | P a g e

www.iiste.org 
[10]. Yüzer, N., 1998. Silis Dumanı katkılı Betonarme Elemanlara Klorür Etkisini Hızlandırılmış Korozyon Deneyi ile Araştırılması, Doktora Tezi, Y.T.Ü. Fen Bilimleri Enstitüsü, İstanbul.

[11]. Şimşek, O., Erdal, M. Ve Sancak, E., Silis Dumanının Çelik Lifli Betonun Eğilme Dayanımına Etkisi, Gazi Üniv.Müh.Mim.Fak.Der.Cilt 20,No 2,s.211-215, 2005, Ankara.

[12]. Köksal, F., Yiğit, İ., Yerlikaya, M., Şahin, Y., Silis Dumanı ve Çelik Tel Kullanımının Yüksek Dayanımlı Betonların Mekanik Özelliklerine Etkisi, 6.Ulusal Beton Kongresi, 16-18 Kasım 2005, İTÜ, Maslak/İstanbul,s.317-326.

[13].ASTM C 1018 American Sosiety of Testing Materials standart1.

[14]. Erdoğdu, S., Kurbetçi, Ş., Doğan, A., Silis Dumanının Katkılı Çimento ile Kullanımı, 4.Ulusal Beton Kongresi Beton Teknolojisinde Mineral ve Kimyasal Katkılar Bildiri Kitab1, TMMOB İMO, İstanbul, s.257-265.

[15]. Ekinçi, C.E., ve Yeğinobalı, A., Silis Dumanı Katkılı Betonların Çarpma Dayanımı, 4.Ulusal Beton Kongresi(TMMOB İMO), s.25-33, Maya Basın Yayın, İstanbul. 